University of Nebraska - Lincoln

DigitalCommons@University of Nebraska - Lincoln

Sociology Department, Faculty Publications

Sociology, Department of

2009

Coping Styles and Sex Differences in Depressive Symptoms and Delinquent Behavior

Lisa A. Kort-Butler

University of Nebraska-Lincoln, lkortbutler2@unl.edu

Follow this and additional works at: https://digitalcommons.unl.edu/sociologyfacpub

Part of the Criminology Commons, Gender and Sexuality Commons, and the Medicine and Health Commons

Kort-Butler, Lisa A., "Coping Styles and Sex Differences in Depressive Symptoms and Delinquent Behavior" (2009). Sociology Department, Faculty Publications. 193.

https://digitalcommons.unl.edu/sociologyfacpub/193

This Article is brought to you for free and open access by the Sociology, Department of at DigitalCommons@University of Nebraska - Lincoln. It has been accepted for inclusion in Sociology Department, Faculty Publications by an authorized administrator of DigitalCommons@University of Nebraska - Lincoln. 


\title{
Coping Styles and Sex Differences in Depressive Symptoms and Delinquent Behavior
}

\author{
Lisa A. Kort-Butler \\ Department of Sociology, University of Nebraska-Lincoln, Lincoln, NE, USA; email lkortbutler2@unl.edu
}

\begin{abstract}
Building on research that links gender to differences in well-being and differences in stress exposure and vulnerability, the current study examines how coping styles are gendered in ways that may contribute to sex differences in depressive symptoms and delinquent behavior. The study disaggregates stress measures to reflect gender differences in the experience of stress, examining whether avoidant, approach, and action coping condition the relationship between stress and well-being. Regression analyses were conducted using data from the National Longitudinal Study of Adolescent Health. Results revealed sex differences and similarities. The interaction of avoidant coping and stress helped explain why girls had more depressive symptoms than boys, action coping increased delinquent behavior for girls, while approach coping decreased delinquent behavior for boys and girls. Assisting adolescents in developing coping styles that discourage avoiding problems or taking quick action, but that encourage problem-solving, can improve well-being, regardless of sex
\end{abstract}

Keywords: Sex differences, Stress, Coping, Depression, Delinquency

Adolescence is the period during which sex differences in depressive symptoms and delinquent behavior emerge. Girls begin to demonstrate higher levels of depressive symptoms than do boys, while boys begin to engage in more antisocial behavior than do girls (Aarons et al. 2001; Garland et al. 2001; Kessler et al. 1994). This is also the period in which young people begin to try out adult statuses, rehearse culturally appropri- ate gender definitions, and solidify gender identities (Hagan and Foster 2001). Considering this conjunction, adolescence is an ideal period to study sex differences in depressive symptoms and delinquent behaviors (Barrett and White 2002). In recent years, there has been growing interest in the possibility of a common etiology for criminal behavior and emotional distress (De Coster and Heimer 2001; Hagan et al. 2002; Rosenfield et al. 2005). Some researchers have taken an integrative approach, studying both types of behaviors simultaneously, with particular interest in understanding gender differences (Hagan and Foster 2003; Meadows 2007). One line of research focuses on how gendered variations in the stress process culminate in these sex-differences in depressive symptoms and delinquent behavior (Broidy and Agnew 1997; De Coster 2005; Kim et al. 2003). This article builds on research that links gender to differences in outcomes and to differences in stress exposure and vulnerability. The current study expands this research by examining how coping styles are gendered in ways that may contribute to sex differences in depressive symptoms and delinquent behavior. An examination of the interaction of stress and coping styles can contribute to a more detailed account of differential responses to gendered stressors.

The current study draws on general strain theory (GST) (Agnew 1992), an approach to delinquent behavior which mirrors the stress paradigm (Pearlin 1989). Both describe similar processes leading from the experience of stress to problems with well-being. The stress paradigm suggests that stressful experiences tax the individual's ability to adapt, the lack of psychosocial re- 
sources detract from healthy adaptation, and the inability to adapt threatens mental health (Aneshensel 1992). Psychosocial resources can be viewed as moderating or buffering constructs, which may hinder, prevent, or advance adaptations to stress (Pearlin 1999). The overriding argument of GST is that strain, defined as adolescents' negative experiences and negative relations with others, gives rise to negative affect. Inability or failure to manage negative affect legitimately may lead to illegitimate modes of adaptation, such as delinquent behavior (Agnew 1992). Further, the impact of strain on delinquent behavior is conditioned by several variables, including psychosocial resources (Agnew 1992). In addition, both of these approaches have "space" for theorizing about the effects of gender. Although the nature of the models posited by GST and the stress paradigm is thought to be similar across sex, the differences within the process, created by a gendered social structure, may result in different outcomes.

\section{Gender, Stress, and Coping}

Theoretical work suggests that through the process of gender socialization and social interaction, cultural messages about the place and value of males and females in relation to others in the social world become intimately linked to assumptions about the self (Gilligan 1982; Heimer 1996; Horwitz and White 1987; Rosenfield et al. 2005). Males' and females' positions in the social structure contain different cultural messages. For males, these messages deemphasize their connection to others, foster individuation and independence, and support a higher sense of self-salience. Consequently, a strong sense of independence from others and others' feelings may free them to act out against others more easily. Further, a focus on personal interests and feelings to the exclusion of others' feelings may make it difficult to turn negative emotions inward (Heimer et al. 2006). As a result, males may be more likely to experience conduct problems like delinquency.

In contrast, for females, these messages emphasize their connection to others, foster reliance on and empathy for others, and lead to a lower sense of self-salience. Consequently, a sense of interconnectedness and concern for others' feelings and the low priority placed on the self may lead them to turn negative emotions inward. Further, empathizing with others may impede behavior that might harm or jeopardize relationships with others (Heimer et al. 2006). As a result, females may be more likely to experience problems like depression.

Research that relies on counts of stressful life events to assess stress exposure has been able to explain only a small portion of the gender gap in either depressive symptoms or delinquent behavior (Dornbusch et al.
1991; Gore et al. 1992; Van Gundy 2002). In contrast, by specifying the nature of stressful life events, Turner et al. (1995) demonstrated that observing life events happening to others, as well as personally experiencing recent and chronic stressful events, explained females' higher levels of depressive symptoms. It is not simply a matter of who has more stress, but who experiences what kind of stress (Compas and Wagner 1991; De Coster 2005; Kessler and McLeod 1984).

Researchers distinguish between those stressors oriented around the agency of the individual in terms of competence, success, and individuality, and those oriented around relationships with others (De Coster 2005; Eagly et al. 2000). The former, agentic stressors, are intrapersonal in nature, having personal relevance regarding an individual's goals or competence (e.g., threats to personal achievement and life goals) or events that happen primarily to the individual (e.g., victimization). The latter, communal stressors, are interpersonal in nature, involving another person (e.g., difficulties with family or peers) or difficulties that impact another person in the individual's social network (e.g., something bad happens to a family member or friend).

Because their perceptions of stress are keyed to their locations in the social structure and socialization experiences, males and females may be attuned to different kinds of stressors (Davis et al. 1999; Rosenfield 1999). Males may be more focused on agentic stressors, and females may be more focused on communal stressors (De Coster 2005; Eagly et al. 2000). Research demonstrates that adolescent males report more exposure to agentic stressors, like impediments to personal achievements and physical victimization, and adolescent females report more exposure to communal stressors, like difficulties among those in their social networks and relational problems with family and friends (Compas and Wagner 1991; Gore et al. 1992; Liu and Kaplan 1999; Sweeting and West 1994).

If males and females are differentially exposed to certain types of stress, it may be that they are differentially vulnerable to these types of stress (Mirowsky and Ross 1989; Rosenfield 1999; Turner and Avison 1989). Studies reveal that males are more responsive to achievementrelated stress and victimization, whereas females are more responsive to family and peer-related stress (Larson and Asmussen 1991; Mazerolle 1998; Turner et al. 1995). Notably, De Coster (2005) found that girls were more vulnerable to family and peer stressors, contributing to depressive symptoms, whereas boys were more vulnerable to victimization and achievement-related stressors, contributing to delinquent behavior. Thus, research suggests that it is necessary to examine general stress as well as gendered stress in order to discern possible variations that may contribute to sex differences in well-being (Hoffman and Su 1997; Thoits 1995). 
Like perceptions of stress, males' and females' development and use of coping styles are keyed to their locations in the social structure and socialization experiences. Coping styles are habitual preferences for approaching problems, which are employed when facing stressors across a variety of situations (Thoits 1995). Compas et al. (1993) describe how, through socialization practices, boys and girls may develop different coping styles. Consistent with traditional definitions of masculinity and femininity, males may draw on a coping style that reflects the emphasis placed on social distance (e.g., face the problem, deal with it yourself), whereas females may draw on a coping style that reflects the emphasis placed on social relationships (e.g., avoid confrontation, emotional rumination) (Leadbeater et al. 1995; Rosenfield 1999).

Research indicates that males and females differ in the coping styles on which they are likely to rely (Byrne 2000; Thoits 1995). Research suggests that adolescent boys tend to have an approach-oriented or problem-focused coping style, wherein they try to control their emotions, try to control the situation, focus on positive aspects of the situation, and engage in individualized problem-solving efforts. Adolescent girls tend to have an avoidant or emotion-focused style, wherein they express their emotions, distract themselves, focus on negative aspects of the situation, and seek social support (Allison et al. 1997; Compas et al. 1993; Frydenberg and Lewis 1993; Seiffge-Krenke 1993).

If there are sex differences in coping styles, the gender distinctions described above also have important implications for the conditioning effects coping styles may have in the relationship between stress and wellbeing. Research suggests an avoidant coping style may inhibit problem-focused coping and instrumental behavior, as well as undermine a sense of control, adding to depressed affect (Compas et al. 1993; Liu and Kaplan 1999; Seiffge-Krenke and Klessinger 2000). Therefore, an avoidant coping style may buffer the negative effect of stress on delinquent behavior, but amplify the negative effect of stress on depressive symptoms. If so, this could contribute to lower levels of delinquent behavior for girls but higher levels of depressive symptoms, relative to boys.

Research suggests an approach-oriented coping style facilitates problem-solving and a sense of control, lessening depressed affect. However, conduct problems can be exacerbated if approach coping is not tempered by restraint, such as simply taking action to deal with problem. (Compas et al. 1993; Liu and Kaplan 1999; Seiffge-Krenke and Klessinger 2000). Therefore, an approach coping style may amplify the negative effect of stress on delinquent behavior, but buffer the negative effect of stress on depressive symptoms. If so, this could contribute to lower levels of depressive symptoms for boys but higher levels of delinquent behavior, relative to girls.

Hypotheses

First, sex differences in the experience of stress may translate into sex differences in the reaction to stress, reflected by delinquent behavior and depressive symptoms. General stress measures may mask sex differences. If agentic stress is more salient for boys' delinquent behavior and communal stress is more salient for girls' depressive symptoms, I hypothesize a significant difference between the stress regression coefficients for boys and girls in direct effects models. Second, sex differences in coping styles may translate into sex differences in well-being. If boys' lower levels of avoidant coping and higher levels of approach coping contribute to delinquent behavior but inhibit depressive symptoms relative to girls, I hypothesize a significant difference between the coping regression coefficients for boys and girls in direct effects models. Additionally, if girls' higher levels of avoidant coping and lower levels of approach coping inhibit delinquent behavior but contribute to depressive symptoms relative to boys, I hypothesize a significant difference between the coping regression coefficients for boys and girls in direct effects models.

Finally, sex differences in stress and coping styles may translate into differences in the conditioning effects coping styles have between stress and well-being. For example, girls may be more vulnerable to depressive outcomes in response to communal stress, and girls may rely more exclusively on an avoidant coping style. For girls, I hypothesize that an avoidant coping style interacts positively with communal stress, contributing to higher levels of depressive symptoms. Also, I hypothesize that an avoidant coping style interacts negatively with communal stress, contributing to lower levels of delinquent behavior. As another example, boys may be more vulnerable to delinquent outcomes in response to agentic stress, and boys may rely more exclusively on an approach coping style. For boys, I hypothesize that an approach coping style interacts positively with agentic stress, contributing to higher levels of delinquent behavior. Also, I hypothesize that an approach coping style interacts negatively with agentic stress, contributing to lower levels of depressive symptoms.

\section{Methodology}

Data and Participants

The data were from the National Longitudinal Study of Adolescent Health (Add Health). The data have been 
discussed in detail elsewhere (Bearman et al. 1997); here I provide an overview. The study is a nationally representative, probability-based survey of adolescents in grades seven through twelve. The study employed a stratified, random sample design of all high schools in the United States. High schools were stratified by region, urbanicity, school size and type, grade span, and percent white and black. In all, 80 high schools and 52 middle or "feeder" schools were selected with unequal probability of selection. The high schools became the cluster identifier, thus the primary sampling units for participants. For each school sampled, questionnaires were collected from students present on the day of administration. Then, a nationally representative sample of students (and their parents) from the school rosters and from those who completed the In- School Questionnaire were selected to participate in the in-home data collection phase on which the present study is based. Wave 1 in-home interviews were conducted in 1995, and Wave 2 interviews were conducted in 1996.

The sample used in the current analysis consisted of 5,954 males and 6,316 females. The average age was 15.8 years and the average household income was $\$ 46,100$. The racial/ethnic distribution of the sample was $54.6 \%$ white, $21.0 \%$ black, $15.3 \%$ Hispanic origin, and 9.1\% Asian-Pacific Islander, Native American, and other origin. In this sample, $71 \%$ of respondents lived in twoparent families and $29 \%$ lived in single-parent families.

\section{Measures}

Measures of demographic characteristics, baseline levels of delinquent behavior and depressive symptoms, and Time 1 measures of family relationships were drawn from Wave 1. Measures of the independent and dependent variables were drawn from Wave 2. Udry (2004) states that many sources were consulted to develop and construct the Add Health survey, but that no scales from the literature remained entirely intact in the final instrument. Udry (2004) suggested the use of alpha reliability of summed scales and principal components factor analysis to validate items in research. Both approaches were employed in constructing items. Unless otherwise specified, an additive approach was used to construct scales.

\section{Delinquent Behavior}

Delinquent behavior was measured with a 15-item scale covering a variety of activities as reported in the past 12 months $(\alpha=.77)$. The activities include status offenses (e.g., running away, truancy), minor delinquent behavior (e.g., vandalism, shoplifting), and more serious forms of property and violent delinquent behavior (e.g., burglary, assault). The response categories range from zero ("never") to three ("five or more times"). The scale also incorporates measures of frequency of alcohol use in the past 12 months, ranging from zero (never) to three (3-7 days a week). The same items were included on the baseline measure of delinquent behavior.

\section{Depressive Symptoms}

Depressive symptoms were measured with a 16-item scale $(\alpha=.86)$, and included statements such as "you felt depressed," "you thought your life had been a failure," "you didn't feel like eating, your appetite was poor," and "it was hard to get started doing things." The same items were included on the baseline measure of depressive symptoms. The scale was based on the CES-D (Radloff 1977), a self-report symptom scale designed for use in nonclinical populations.

\section{General Stress}

The general stress measure incorporated all of the stress variables described below, as well as respondents' assessments of their school and neighborhood environments $(\alpha=.81)$. To create a composite stress measure, the scores of each individual stress variable were standardized; these z-scores were then summed. Divisions into categories of stress were derived from both groupings common in previous literature, as well as through factor analyses.

In factor analysis, the school and neighborhood variables loaded on a factor distinct from agentic and communal stress, which could be called ambient stress (Aneshensel and Sucoff 1996). The school variable was based on four items that asked students about their school experience, such as the adolescents' feelings that they were part of school, safe at school, close to others at school, and happy to be at their school $(\alpha=.77)$. The neighborhood variable was based on six items assessing respondents' happiness living in their neighborhood, their perceptions about safety, and whether people in the neighborhood know and look out for each other $(\alpha=$ .60). Although these items were included in the general stress measure, theory did not seem to suggest ambient stress is gendered. Therefore I did not conduct a separate regression analyses by sex.

\section{Agentic Stress}

The agentic stress measure included violent victimization, academic trouble, and adolescents' assessments of their life chances $(\alpha=.65)$. Again, a composite score was created using standardized variables. The violent victimization variable consisted of four items assessing the extent to which the respondent was a victim of violence in the past year, including being threatened by 
and/or injured with a weapon, and witnessing violence $(\alpha=.68)$. The academic trouble variable tapped respondents' difficulties paying attention in school and finishing homework, as well as difficulties "getting along" with teachers and if they thought teachers at their school treated students fairly $(\alpha=.65)$. The life chances variable consisted of six items representing respondents' evaluation of their chances of being killed, living to middleage, staying HIV-free, graduating from college, getting married, and achieving a middle-class income by middle-age $(\alpha=.59)$.

\section{Communal Stress}

The communal stress measure included difficulties with other people, trouble relating with other students, and change in relationship with family $(\alpha=.67)$. As above, a composite score was created using standardized variables. The measure of difficulties with other people consisted of two items asking respondents if they felt people were unfriendly to them or disliked them $(\alpha$ $=.67$ ). The measure of the respondent's trouble relating with students asked respondents if they had problems "getting along" with other students and if students at their school were prejudiced $(\alpha=.18)$. The family relationship variable was constructed to capture a shift in the adolescents' relationships with their families. The variable was based on four items that assessed how adolescents felt about the quality of their family relationship, such as the family having fun together, feeling family members pay attention to and understand the respondent, and the respondent's desire to leave home $(\alpha=.72)$. To create a measure that captured the change in family-adolescent relationship, the value of the variable at Wave 2 was divided by the value at Wave 1. A ratio approach was chosen to overcome the interpretative challenge posed by negative scores. By using a ratio, 1 equals no change, values less than 1 represent relationship decline, and values greater than 1 represent improvement.

\section{Coping Styles}

Coping styles were divided into three categories indicated in the previous literature and/or indicated through factor analysis: avoidant coping, approach coping, and action coping. For each coping measure, a higher score denotes greater endorsement of that coping style. Factor analysis indicated that four items representing avoidant and approach coping styles loaded on the same factor. However, the avoidant coping items loaded higher (>.75), while the approach coping items loaded relatively low (<.30). Therefore, these items were separated into two categories.

\section{Avoidant Coping}

The avoidant coping measure consists of two items: "you usually go out of your way to avoid having to deal with problems in your life" and "difficult problems make you very upset" $(\alpha=.48)$. $\alpha$

\section{Approach Coping}

The approach coping measure consists of two items: "after carrying out a solution to a problem, you usually try to think about what went right and what went wrong," and "when you get what you want, it's usually because you worked hard for it" $(\alpha=.21)$. The avoidant and approach coping items are consistent with other literature. For instance, on the Coping Responses Inventory described by Moos (2002), avoidant coping is characterized by cognitive avoidance and resignation, whereas approach coping is characterized by logical analysis and positive reappraisal. The items are also similar to items found on the Children's Coping Strategies Checklist (Ayers et al. 1996), which Gonzales et al. (2001) used in their research.

\section{Action Coping}

Although other researchers have placed approachand action-oriented items on the same scale using reverse coding (Gonzales et al. 2001), the factor analysis indicated a separate variable. The action coping measure was comprised of two items: "when making decisions, you usually go with your 'gut feeling' without thinking too much about the consequences of each alternative" and "you live your life without much thought for the future" $(\alpha=.49)$. These items are in direct contrast to the problem-solving orientation of the approach coping items, and reflect a more impulsive, present-oriented style of decision-making. The analyses utilized standardized scores of each coping variable.

\section{Control Variables}

Age, race/ethnicity, household income, and family structure were included as statistical controls, given the theoretical and empirical connection between social status and well-being. The respondent's age was calculated by subtracting the respondent's birth year from the interview year. Race was a dummy variable where White was the reference group. Household income was the parent's Wave 1 report of annual household income. ${ }^{1}$

1. A multiple regression imputation was used to handle missing income cases, for which $22 \%$ of the data was missing. The imputed regression equation includes the interviewed parent's marital status, interviewed parent's highest level of education, highest level of education of that parent's partner (if there was one), 
Family structure, described at Wave 2, was a dummy variable where two-parent household served as the reference group. As statistical controls against potential selection effects, Time 1 measures of delinquent behavior and depressive symptoms were included in their respective models.

\section{Analysis Plan}

To carry out the analysis, cases missing the Wave 2 weighting variables and the biological sex variable were deleted. Further, selected cases included those respondents who were not married, still in middle or high school, and living with at least one parental figure. The final sample size for analysis was 12,270 . For missing cases a mean substitution was employed. For the independent variables, the number of missing was small, ranging from less than .5\% of the sample missing (coping variables) to $3 \%$ missing (delinquent behavior). A mean substitution approach was suitable in these cases. For female respondents with missing data, the mean was calculated for only female respondents; the same process was used for male respondents. Overall, analyses indicated that this method for managing missing data did not alter the substantive results (see Hawkins et al. (2006) who also employed a mean substitution method in their analysis of Add Health data.).

All analyses that involved estimates of the mean and regression estimates incorporated the weighting techniques advised by Chantala and Tabor (1999). As with much delinquency research, the delinquent behavior variable had a large number of zero values and a positive skew. The variable was also overdispersed, with the standard deviation exceeding the mean. The regression analyses of delinquent behavior therefore relied on negative binomial regression models (see Haynie et al. (2005) who also used this approach in their analysis of Add Health). The depressive symptoms variable did not exhibit problems with skewness or overdispersion, so analyses of depressive symptoms relied on ordinary least-squares regression. Although the different regression techniques do not allow for comparison of the relative strength or magnitude of the effect of a coping variable on each outcome, the concern of the current paper is determining if there is a difference in how coping

(Note 1, continued) respondent's race, reported ability to pay bills, and receipt of food stamps. After confirming the equation for cases not missing income by regressing income on these variables, missing income cases were replaced with the predicted value. To determine if those respondents who did not report income (i.e., missing before replacement) were systematically different than those who did, a dummy variable for those who did not report income was included in a preliminary regression analyses on outcome. The coefficient was not significant, indicating no difference, so the dummy variable was excluded from further analyses. influences outcome. To this extent, results from the regression models for delinquent behavior and depressive symptoms are comparable.

Frydenberg et al. (2003) argue that stress may lead to a variety of coping responses, some of which may be conflicting, both within and across individuals. Thus, the particular effects of one style of coping could be masked if styles are examined conjointly. In order to capture the specific effects of each coping style, three series of regression models were run. The first series included models in which the composite stress measures, avoidant coping, and their interactions were regressed on delinquent behavior and depressive symptoms. The second series included models in which the composite stress measures, approach coping, and their interactions were regressed on delinquent behavior and depressive symptoms. The third series included models in which the composite stress measures, action coping, and their interactions were regressed on delinquent behavior and depressive symptoms. Interaction terms were computed by multiplying the standardized scores of the coping and stress variables. The use of regression with interaction terms is consistent with general strain theory research regarding the impact of conditioning variables (Agnew and White 1992; Baron 2007; Jang and Johnson 2003; Robbers 2004).

\section{Results}

Table 1 illustrates means, standard deviations, and t-tests for delinquent behavior, depressive symptoms, stress, and coping variables. Consistent with previous research, $t$-tests confirmed that boys reported more delinquent involvement than girls, but girls reported higher levels of depressive symptoms. Boys and girls did not differ with regard to total stress. Consistent with previous work, boys reported significantly higher levels of agentic stressors compared to girls. In particular, boys reported greater levels of victimization, concern over life chances, and academic trouble. There was no sex difference among the communal stressors. Girls reported more ambient stress, both at school and in their neighborhoods. The $t$-tests confirmed that girls reported greater endorsement of avoidant coping, but boys reported greater endorsement of action coping. Boys and girls did not differ with regard to approach coping.

The control variables were regressed on delinquent behavior and depressive symptoms. In their respective models, prior delinquent behavior and depressive symptoms were positively related to Wave 2 outcome. For males and females, Black adolescents were less likely to be delinquent, but adolescents from single parent homes were more likely to be delinquent. Additionally, females of other races were less likely to be delin- 
Table 1. T-tests for differences in means

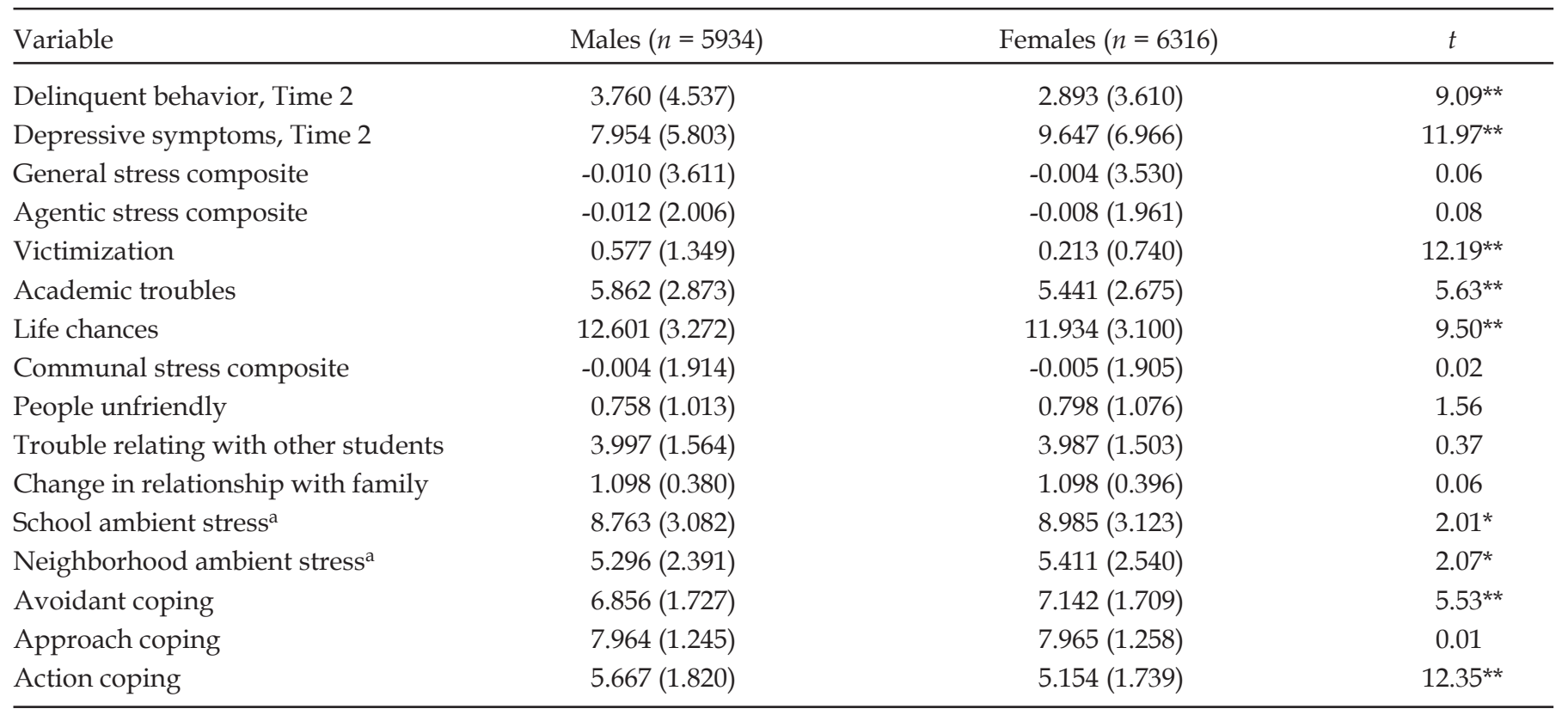

Means with standard deviations in parentheses

${ }^{* *} p<0.01 ; * p<0.05$ (two-tailed tests)

a. These items are included in the general stress composite, but are excluded from analyses by sex, so no ambient stress composite is computed

quent. For males and females, Hispanic adolescents and adolescents from single parent homes were more likely to be depressed. Additionally, for females, household income was negatively related to depressive symptoms. The effects of the control variables were mostly stable across models. Therefore, the regression analyses below included all the controls, but Tables 2, 3, and 4 show only the coefficients for the independent variables.

Table 2 depicts the models in which stress, avoidant coping, and their interactions were regressed on delinquent behavior and depressive symptoms. In Model 1a, each stress measure was positively related to delinquent behavior, but $z$-scores indicated no differences between the coefficients for males and females. In Model 1a, in the regression that includes agentic stress, avoidant coping was significantly related to delinquent behavior for girls, and the coefficient was significantly different from boys. Avoidant coping, as a direct effect, increased delinquent behavior for girls. In Model $1 \mathrm{~b}$, for general and communal stress, the interaction with avoidant coping was significant only for boys, indicating a buffering effect: as avoidant coping increases, the effect of stress on delinquent behavior decreases. For agentic stress, the interaction with avoidant coping was significant for boys and girls. In no case were the interaction coefficients for boys and girls significantly different, but the pattern of the results suggests that the buffering effect of avoidant coping was especially important for limiting boys' delinquent behavior.
The patterns for depressive symptoms were different. In Model 2a, all of the stress measures were positively related to depressive symptoms for both boys and girls, and $z$-scores demonstrated that general and communal stress were more salient predictors of depressive symptoms for girls. In Model $2 \mathrm{a}$, avoidant coping increased depressive symptoms for boys and girls. The $z$-scores indicated no significant sex difference between these coefficients. In Model 2b, the interactions of avoidant coping with general and communal stress were significant only for girls, indicating an amplifying effect: as avoidant coping increases, the effect of stress on depressive symptoms increases. However, $z$-scores indicate no difference between the interaction coefficients for males and females in either of these models. Overall, the pattern suggests that avoidant coping promoted depressive symptoms for both boys and girls, and for girls, it appeared to amplify the effect of general and communal stress. However, because the interaction coefficients were not significantly different, avoidant coping did not fully account for girls' greater vulnerability to depressive outcomes of general and communal stress.

Table 3 depicts the models in which stress, approach coping, and their interactions were regressed on delinquent behavior and depressive symptoms. In Model 1a, each stress measure was positively related to delinquent behavior, but $z$-scores indicated no sex differences between the general and communal stress coefficients. The difference between the agentic stress coefficients neared 


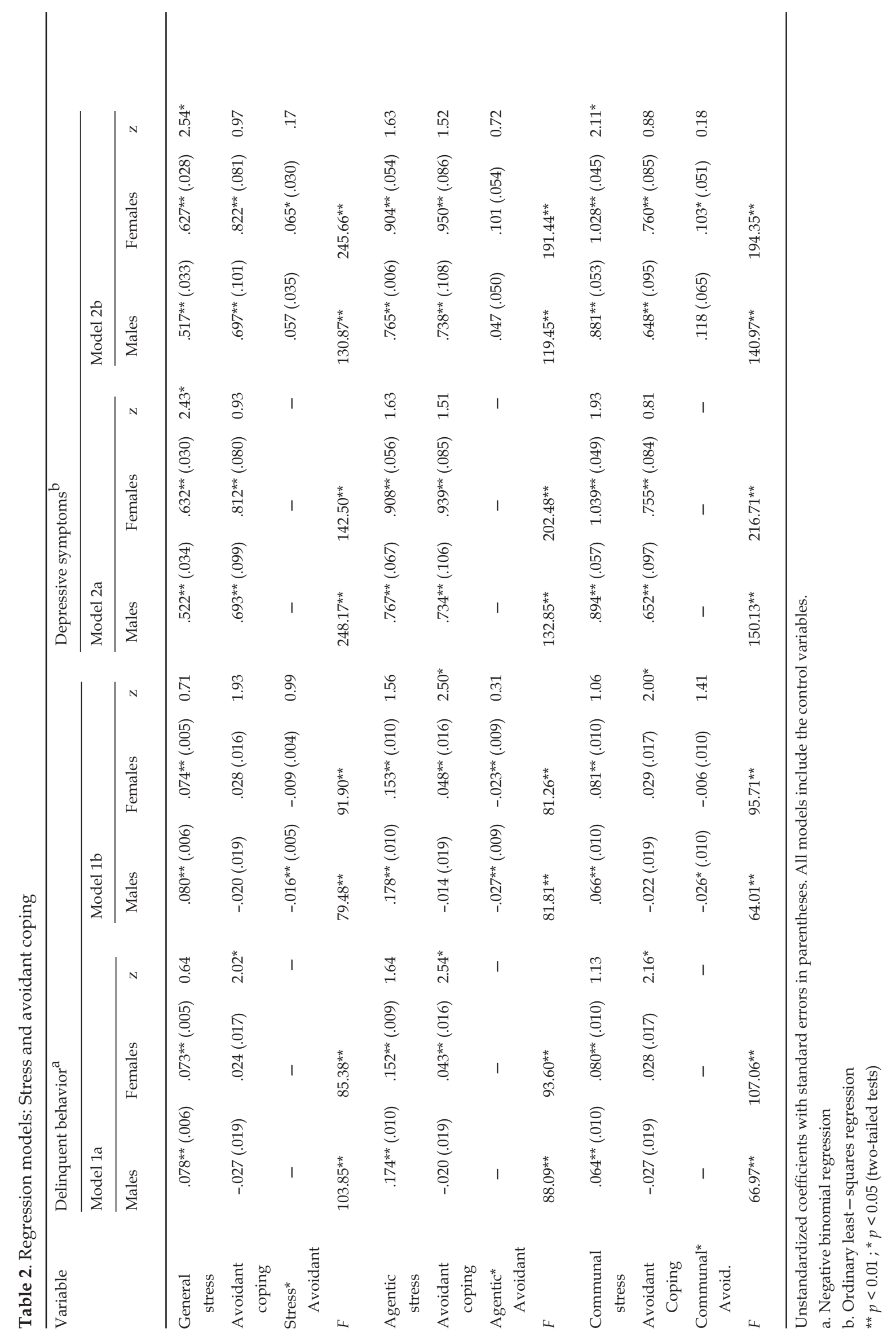




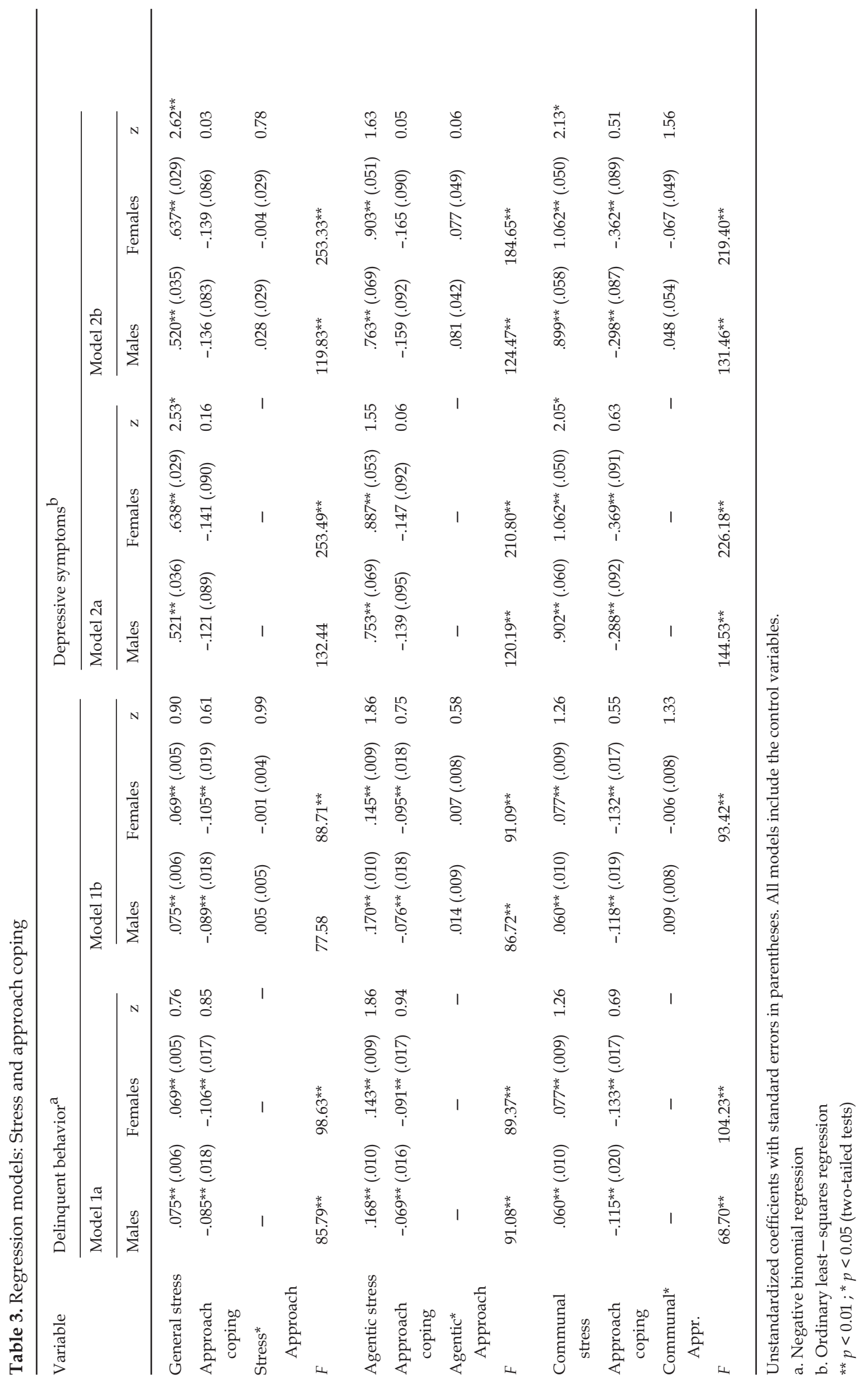


significance, suggesting boys were more vulnerable to a delinquent outcome of agentic stress. Approach coping had a negative effect on delinquent behavior for boys and girls, but $z$-scores indicated no significant sex difference. In Model 1b, for each measure of stress, the interaction with approach coping was not significant.

Approach coping was mostly unrelated to depressive symptoms. In Model 2a, all of the stress composite measures were positively related to depressive symptoms for both boys and girls, and $z$-scores again demonstrated that general and communal stress were more salient predictors of depressive symptoms for girls. In Model 2a, the regression that includes communal stress shows that approach coping was negatively related to depressive symptoms for both boy and girls, but the $z$-score indicated no significant sex difference. In Model 2b, the interaction terms between each type of stress and approach coping were not significant. Approach coping did not account for girls' greater vulnerability to depressive outcomes of general and communal stress.

Table 4 depicts the models in which stress, action coping, and their interactions were regressed on delinquent behavior and depressive symptoms. In Model 1a, each stress measure was positively related to delinquent behavior, but $z$-scores indicated no sex differences between the general and communal stress coefficients. The difference between the agentic stress coefficients was significant, indicating that boys were more vulnerable to delinquent outcomes of agentic stress. In the regressions including general and agentic stress, action coping had a direct effect for females only, increasing delinquent behavior. In the model including communal stress, action coping had a positive effect for males and females. The $z$-scores indicated that in all models the direct effect of action coping was significantly more salient for girls. In Model 1b, the interactions of action coping with general stress and with communal stress were not significant. The interaction of agentic stress with action coping is significant for males and females, indicating a buffering effect: as action coping increases, the effect of agentic stress on delinquent behavior decreases. The $z$-score indicated no sex difference between the interaction coefficients, so action coping does not account for males' greater vulnerability to agentic stress. Overall the pattern suggests that action coping promoted delinquent behavior for both boys and girls, yet it was more salient for girls. Interestingly, action coping, in the context of agentic stress, was an important resource for limiting delinquent behavior in boys and girls.

In the regressions on depressive symptoms, in Model 2a, all of the stress measures were positively related to depressive symptoms for both boys and girls, and $z$-scores demonstrate that general and communal stress were more salient predictors of depressive symptoms for girls. Action coping was positively related to depressive symptoms for boys and girls, such that greater action coping increases depressive symptoms. Comparing coefficients for action coping showed no significant sex difference. In Model $2 b$, the interaction terms between each type of stress and action coping were not significant. Action coping did not account for girls' greater vulnerability to general and communal stress.

\section{Discussion}

This article examined how sex differences in stress and coping styles may interact in ways that contribute to differences in outcomes. Consistent with previous literature on adolescent well-being, this analysis found that boys reported higher levels of delinquent behavior, whereas girls reported higher levels of depressive symptoms. The hypotheses posed above were partly resolved by this analysis. First, there were sex differences in the stress exposure and vulnerability that contributed to sex differences in well-being. Specifically, boys reported higher levels of agentic stressors, and this type of stress appeared to be a more salient predictor of delinquent behavior for boys relative to girls. Although girls did not report greater exposure to stress, general and communal stress appeared to be more salient predictors of depressive symptoms for girls relative to boys.

Second, there were sex differences in coping styles, but these did not readily explain sex differences in wellbeing as hypothesized. Consistent with previous work, girls and boys reported differences in the coping styles they employ, with girls reporting greater endorsement of an avoidant coping style, and boys reporting greater endorsement of an action coping style (Byrne 2000; Compas et al. 1993). There was no difference in mean levels of an approach coping style oriented around problem-solving, as noted in other research (Frydenberg and Lewis 1993; Washburn-Ormachea et al. 2004). As direct effects in regression models, there were similarities between boys and girls: approach coping was negatively related to delinquent behavior, where as avoidant and action coping were positively related to depressive symptoms.

Finally, sex differences in stress and coping styles did not readily translate into differences in the conditioning effect of coping styles between stress and wellbeing. The finding most consistent with previous work was that, for girls, avoidant coping interacted with stress to amplify the negative effect of stress on depressive symptoms. The finding also supports the notion that gender distinctions encourage girls to avoid directly confronting problems, but to engage in emotional attentiveness or rumination, contributing to de- 


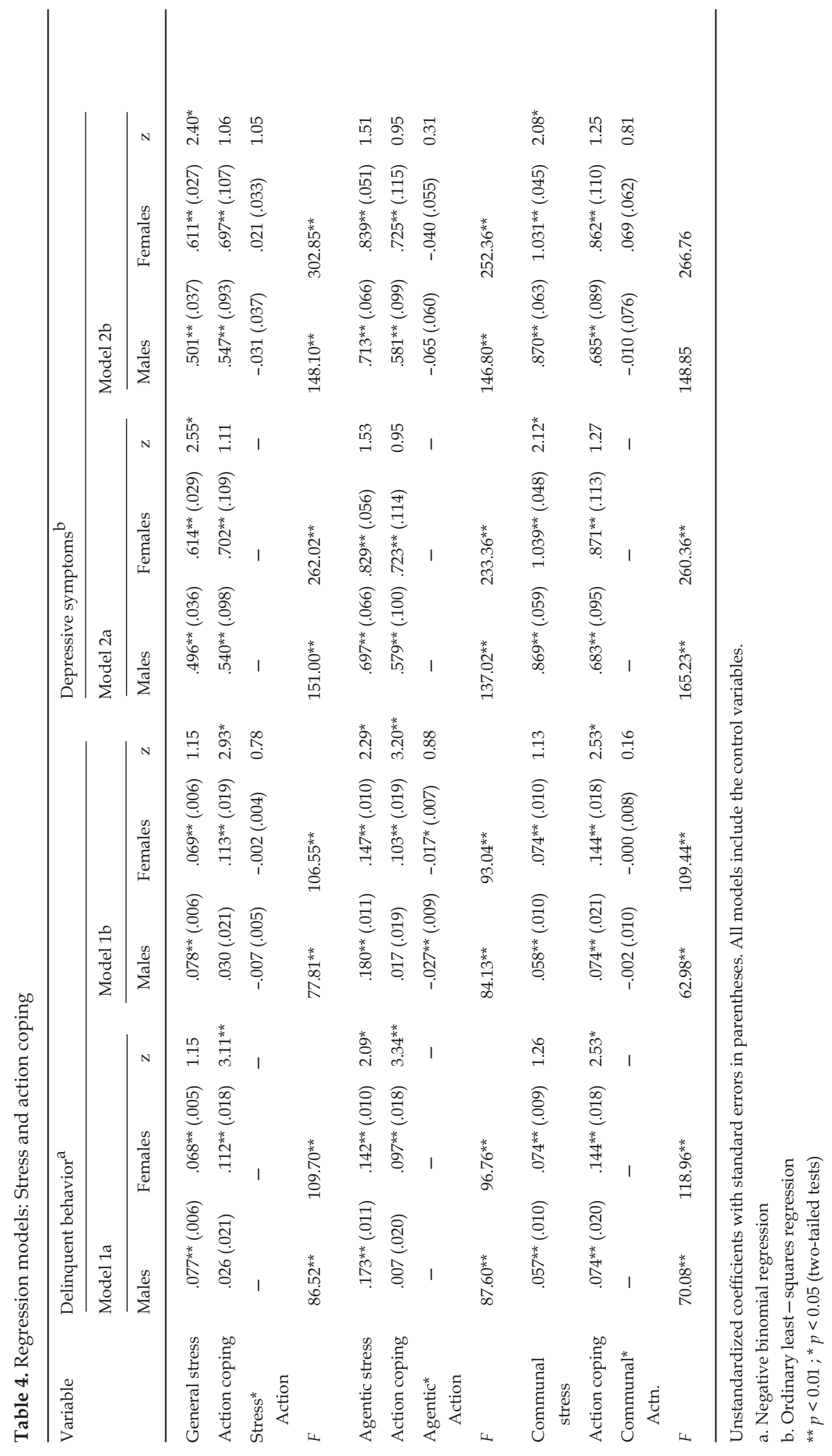


pressive symptoms (Compas et al. 1993; Leadbeater et al. 1995; Liu and Kaplan 1999; Seiffge-Krenke and Klessinger 2000). Thus, girls' emphasis on an avoidant coping in response to the kinds of stress to which they are more vulnerable may contribute to sex differences in depressive symptoms.

Avoidant coping contributed to boys' depressive symptoms, but it also had the unexpected effect of buffering the damaging effect of stress on delinquent behavior. Gonzales et al. (2001) also found that avoidant coping, at high levels of stress, may promote prosocial behavior. Agnew (1992) posits that delinquent behavior can be viewed as retaliation against the source of the strain. When boys avoid the source of a problem, it could potentially limit contact with a person or situation that otherwise might provoke a delinquent reaction. In this sense, avoidant coping amounts to "cooling off." The notion that boys' greater vulnerability to agentic stress and greater emphasis on an approach- or actionoriented coping style could contribute to their higher levels of delinquent behavior was not supported by the current analysis. Thus, the conditioning effect of coping styles does not appear to play a large role in sex differences in delinquent behavior.

A key premise of the current project is that the gendering of stress and of coping styles may contribute to sex differences in well-being. Although some difference was evident, there was also a great deal of similarity. For example, in the delinquent behavior models, the interaction terms for agentic stress with avoidant and with action coping were significant for both sexes. Another similarity was that approach coping curtailed delinquent behavior across sex. Other studies indicate that both sexes endorse an approach coping style to the same extent, but may take advantage of such problem-solving strategies in different life domains (Frydenberg and Lewis 1993; Griffith et al. 2000). Females do so in interpersonal and family situations, whereas males do so in confrontational, educational, and occupational situations (Gonzales et al. 2001; Rosenfield 1999; Thoits 1995). The stress measures employed in the current analysis cross life domains, which may conceal differences in how boys and girls apply approach-oriented and other coping styles to stress. Future research should consider life domains, and differences within those domains (Agnew 2005; Colten et al. 1991; De Coster and KortButler 2006).

Additionally, for both sexes an avoidant coping style and an action coping style contributed to depressive symptoms. Both of these coping styles, as measured here, could coincide with a defeatist or fatalistic outlook on life. Fatalism refers to the belief that one is relatively powerless over what happens in life, leading to a withdrawal of conscientious effort, because attempts at problem-solving are viewed by the indi- vidual as unlikely to be successful (Aneshensel 1999; Scheid and Horowitz 1999; Wheaton 1983). A fatalistic outlook, a "let the chips fall where they may" attitude that overrides paced and productive problem- solving, promotes depression (Wheaton 1983). For boys and girls, trying to avoid problems or taking a reckless approach to them appears to exacerbate depressive symptoms.

Interestingly, an action coping style can be doubly damaging for girls, contributing to both depressive and delinquent outcomes. For girls, following a gut feeling without considering the implications of that response contributes to delinquent behavior. Previous literature asserts that girls may be less likely to act out relative to boys, because gender definitions impede behavior that could harm relationships with others (Heimer et al. 2006). Again, fatalism may play a role. Scheid and Horowitz (1999) assert that fatalism may be greater in females, given that their social positions are characterized by higher levels of external regulation over individual choices and actions. If girls feel they have nothing to lose socially, then they may be more inclined to take a more reckless approach to resolving issues, leading to delinquent behavior.

One explanation for the limited difference in the effects of coping found in the current analysis is the restricted measurement of coping styles. The coping measures employed reflect the core concepts of each style, but may only hint at how coping styles affect well-being. Other researchers point to an array of features that involve cognitive, emotional, and behavioral orientations (Broidy 2001; Frydenberg and Lewis 1993; Gonzales et al. 2001). An emphasis on coping strategies in specific situations may be more meaningful, such as asking respondents what steps they take when they have a problem with a friend. Future research on sex differences in depressive symptoms and delinquent behavior should consider more detailed accounts of the marshalling of coping resources.

A second explanation of limited difference in the effects of coping may be due to the nature of the analysis, which relied on cross-sectional data. As such, the data limit a true test of the causal-order assumptions suggested by theories of gender identity development, as well as ideas about the process underlying stress, coping, and mental health. At the same time, Agnew (1992) asserts that the effects of stress and any conditioning variables on delinquent behavior are mostly contemporaneous, an assumption supported by cross-sectional analysis. To examine causality in more detail and give greater consideration to selection effects, future research could consider longitudinal approaches, particularly those with shorter follow-up periods, or diary approaches, both of which could capture gender identity development and the process of stress. 
The question remains as to how different boys and girls really are when it comes to the stress process. As Mirowsky and Ross (1995) note in their study of adults, genuine differences in distress can exist between males and females, independent of factors like emotional responsiveness. Furthermore, differences within sex may be as relevant as differences across sex (Rosenfeld 2002). By focusing on differences across sex, researchers may be underestimating the relevance of similarity in understanding well-being more generally (Meadows 2007; Rosenfeld 2002). Meadows (2007) illustrates how the relationship among stress, coping factors, and well-being are similar, even when mean differences in these variables exist between males and females. In other words, an exclusive focus on the question of differences in delinquent behavior and depressive symptoms can overshadow the lessons learned from such research. As shown in the current study, assisting adolescents in developing coping styles that discourage avoiding problems or taking quick action, but that encourage problem-solving, can help them resist depressive symptoms and delinquent behavior, regardless of sex.

Acknowledgments - This article uses data from Add Health, a program project designed by J. Richard Udry, Peter S. Bearman, and Kathleen Mullan Harris, and funded by a grant P01-HD31921 from the Eunice Kennedy Shriver National Institute of Child Health and Human Development, with cooperative funding from 17 other agencies. Special acknowledgment is due Ronald R. Rindfuss and Barbara Entwisle for assistance in the original design. Persons interested in obtaining data files from Add Health should contact Add Health, Carolina Population Center, 123 W. Franklin Street, Chapel Hill, NC 27516-2524 (addhealth@unc.edu). The author wishes to thank Kimberly Tyler and the anonymous reviewers for their comments on earlier drafts of this article.

\section{References}

Aarons, G. P., Brown, S. A., Hough, R. L., Garland, A. F., \& Wood, P. A. (2001). Prevalence of adolescent substance use disorders across five sectors of care. Journal of the American Academy of Adolescent Psychiatry, 40, 419-426.

Agnew, R. (1992). Foundation for a general strain theory of crime and delinquency. Criminology, 30, 47-87.

Agnew, R. (2005). Why do criminals offend? Los Angeles: Roxbury Publishing.

Agnew, R., \& White, H. R. (1992). An empirical test of general strain theory. Criminology, 30, 457-499.

Allison, K. R., Adalf, E. M., \& Mates, D. (1997). Life strain, coping, and substance use among high school students. Addiction Research, 5, 251-272.

Aneshensel, C. S. (1992). Social stress: Theory and research. Annual Review of Sociology, 18, 15-38.

Aneshensel, C. S. (1999). Outcomes of the stress process. In A. V. Horwitz \& T. A. Scheid (Eds.), A handbook for the study of mental health (pp. 211-227). Cambridge: Cambridge University Press.
Aneshensel, C. S., \& Sucoff, C. A. (1996). The neighborhood context of adolescent mental health. Journal Health and Social Behavior, 37, 293-310.

Ayers, T. S., Sandler, I. N., West, S. G., \& Roosa, M. W. (1996). A dispositional and situational assessment of children's coping: Testing alternative theoretical models of coping. Journal of Personality, 64, 923-958.

Baron, S. W. (2007). Street youth, gender, financial strain, and crime: Exploring Broidy and Agnew's extension to general strain theory. Deviant Behavior, 28, 273-302.

Barrett, A. E., \& White, H. R. (2002). Trajectories of gender role orientations in adolescence and early adulthood: A prospective study of the mental health effects of masculinity and femininity. Journal of Health and Social Behavior, 43, 451-468.

Bearman, P. S., Jones, J., \& Udry, J. R. (1997). The national longitudinal study of adolescent health: Research design. Accessed August 27, 2002 at http://www.cpc.unc.edu/addhealth

Broidy, L. (2001). A test of general strain theory. Criminology, $39,9-36$.

Broidy, L., \& Agnew, R. (1997). Gender and crime: A general strain theory perspective. Journal of Research in Crime and Delinquency, 34, 275-306.

Byrne, B. (2000). Relationships between anxiety, fear, self-esteem, and coping strategies in adolescence. Adolescence, 35, 201-215.

Chantala, K., \& Tabor, J. (1999). Strategies to perform a designbased analysis using the add health data. Accessed August 27, 2002 at http://cpc.unc.edu/projects/addhealth/addhealth_home.html

Colten, M. E., Gore, S., \& Aseltine, R. H. (1991). The patterning of distress and disorder in a community sample of high school aged youth. In M. E. Colten \& S. Gore (Eds.), Adolescent stress: Causes and consequences (pp. 157-180). New York: Aldine de Gruyter.

Compas, B. E., Orosan, P. G., \& Grant, K. E. (1993). Adolescent stress and coping: Implications for psychopathology during adolescence. Journal of Adolescence, 16, 331-349.

Compas, B. E., \& Wagner, B. M. (1991). Psychosocial stress during adolescence: Intrapersonal and interpersonal processes. In M. E. Colten \& S. Gore (Eds.), Adolescent stress: Causes and consequences (pp. 67-86). New York: Aldine de Gruyter.

Davis, M. C., Matthews, K. A., \& Twamley, E. W. (1999). Is life more difficult on mars or Venus? A meta-analytic review of sex differences in major and minor life events. Annals of Behavioral Medicine, 21, 83-97.

De Coster, S. (2005). Depression and law violation: Gendered responses to gendered stresses. Sociological Perspectives, 48, 155-187.

De Coster, S., \& Heimer, K. (2001). The relationship between law violation and depression: An interactionist analysis. Criminology, 39, 799-833.

De Coster, S., \& Kort-Butler, L. A. (2006). How general is general strain theory? Assessing determinacy and indeterminacy across life domains. Journal of Research in Crime and Delinquency, 43, 1-29. 
Dornbusch, S. M., Mont-Reynaud, R., Ritter, P. L., Chen, Z., \& Steinberg, L. (1991). Stressful events and their correlates among adolescents of diverse backgrounds. In M. E. Colten \& S. Gore (Eds.), Adolescent stress: Causes and consequences (pp. 111- 130). New York: Aldine de Gruyter.

Eagly, A. H., Wood, W., \& Diekman, A. B. (2000). Social role theory of sex differences and similarities: A current appraisal. In T. Eckles \& H. M. Trautnew (eds.), The developmental social psychology of gender (pp. 123-174). Mahwah, NJ: Lawrence Erlbaum Associates.

Frydenberg, E., \& Lewis, R. (1993). Boys play sport and girls turn to others: Age, gender, and ethnicity as determinants of coping. Journal of Adolescence, 16, 253-266.

Frydenberg, E., Lewis, R., Kennedy, G., Ardila, R., Frindte, W., \& Hanoun, R. (2003). Coping with concerns: An exploratory comparison of australian, columbian, german, and palestinian adolescents. Journal of Youth and Adolescence, 32, 59-66.

Garland, A. F., Hough, R. L., McCabe, K. M., Yeh, M., Wood, P. A., \& Aarons, G. P. (2001). Prevalence of psychiatric disorders in youth across five sectors of care. Journal of the American Academy of Adolescent Psychiatry, 40, 409-418.

Gilligan, C. (1982). In a different voice. Cambridge, MA: Harvard University Press.

Gonzales, N. A., Tein, J., Sandler, I. N., \& Friedman, R. J. (2001).On the limits of coping: Interaction between stress and coping for inner-city adolescents. Journal of Adolescent Research, 16, 372-395.

Gore, S., Aseltine, R. H., \& Colton, M. E. (1992). Social structure, life stress, and depressive symptoms in a high schoolaged population. Journal Health and Social Behavior, 33, 97-113.

Griffith, M. A., Dubow, E. F., \& Ippolito, M. F. (2000). Developmental and cross-situational differences in adolescents' coping strategies. Journal of Youth and Adolescence, 29, 183-204.

Hagan, J., \& Foster, H. (2001). Youth violence and the end of adolescence. American Sociological Review, 66, 874-899.

Hagan, J., \& Foster, H. (2003). S/He's a rebel: Toward a sequential stress theory of delinquency and gendered pathways to disadvantage in emerging adulthood. Social Forces, $82,53-86$.

Hagan, J., McCarthy, B., \& Foster, H. (2002). A gendered theory of delinquency and despair in the life course. Acta Sociologica, 45, 37-46.

Hawkins, D. N., Amato, P. R., \& King, V. (2006). Parent-adolescent involvement: The relative influence of parent gender and residence. Journal of Marriage and Family, 68, 125-136.

Haynie, D. L., Giordano, P. C., Manning, W. D., \& Longmore, M. A. (2005). Adolescent romantic relationships and delinquency involvement. Criminology, 43, 177-210.

Heimer, K. (1996). Gender, interaction, and delinquency: Testing a theory of differential social control. Social Psychological Quarterly, 59, 36-91.

Heimer, K., De Coster, S., \& Unal, H. (2006). Opening the black box: Understanding the social psychology of the gender gap in delinquency. Sociology of Crime, Law, and Deviance, 7, 109- 135.

Hoffman, J. P., \& Su, S. S. (1997). The conditional effects of stress on delinquency and drug use: A strain theory assessment of sex differences. Journal of Research in Crime and Delinquency, 34, 46-78.

Horwitz, A. V., \& White, H. R. (1987). Gender role orientations and styles of pathology among adolescents. Journal of Health and Social Behavior, 28, 158-170.

Jang, S. J., \& Johnson, B. R. (2003). Strain, negative emotions, and deviant coping among African Americans: A test of general strain theory. Journal of Quantitative Criminology, 19, 80-105.

Kessler, R. C., McGonagle, K. A., Zhao, S., Nelson, C. B., Hughes, M., Eshleman, S., Wittchen, H., \& Kendler, K. S. (1994). Lifetime and 12-month prevalence of DSM-III-R psychiatric disorders in the United States. Archives of General Psychiatry, 51, 8-19.

Kessler, R. C., \& McLeod, J. D. (1984). Sex differences in vulnerability to undesirable life events. American Sociological Review, 49, 620-631.

Kim, K. J., Conger, R. D., Elder, G. H., \& Lorenz, F. O. (2003). Reciprocal influences between stressful life events and adolescent internalizing and externalizing problems. Child Development, 74, 127-143.

Larson, R., \& Asmussen, L. (1991). Anger, worry, and hurt in early adolescence: An enlarging world of negative emotion. In M. E. Colten \& S. Gore (Eds.), Adolescent stress: Causes and consequences (pp. 21-42). New York: Aldine de Gruyter.

Leadbeater, B. J., Blatt, S. J., \& Quinlan, D. M. (1995). Genderlinked vulnerabilities to depressive symptoms, stress, and problem behaviors in adolescents. Journal of Research on Adolescence, 5, 1-29.

Liu, X., \& Kaplan, H. B. (1999). Explaining gender differences in symptoms of subjective distress in young adolescents. Stress Medicine, 15, 41-51.

Mazerolle, P. (1998). Gender, general strain, and delinquency: An empirical examination. Justice Quarterly, 15, 65-91.

Meadows, S. O. (2007). Evidence of parallel pathways: Gender similarity in the impact of social support on adolescent depression and delinquency. Social Forces, 85, 1143-1167.

Mirowsky, J., \& Ross, C. E. (1989). Social causes of psychological distress. New York: Aldine de Gruyter.

Mirowsky, J., \& Ross, C. E. (1995). Sex differences in distress: Real or artifact? American Sociology Review, 60, 449-68.

Moos, R. (2002). Life stressors, social resources, and coping skills in youth: Applications to adolescents with chronic disorders. Journal of Adolescent Health, 30S, 22-29.

Pearlin, L. I. (1989). The sociological study of stress. Journal of Health and Social Behavior, 30, 241-256.

Pearlin, L. I. (1999). The stress concept revisited. In C. S. Aneshensel \& J. C. Phelan (Eds.), Handbook of the sociology of mental health (pp. 395-415). New York: Kluwer Academic/ Plenum Publishers.

Radloff, L. S. (1977). The CES-D scale: A self-report depression scale for research in the general population. Applied Psychological Measurement, 1, 385-401. 
Robbers, M. L. P. (2004). Revisiting the moderating effect of social support on strain: A gendered test. Sociological Inquiry, 74, 546-69.

Rosenfeld, R. A. (2002). What do we learn about difference from the scholarship on gender. Social Forces, 81, 1-24.

Rosenfield, S. (1999). Gender and mental health: Do women have more psychopathology, men more, or both the same (and why)? In A. V. Horwitz \& T. L. Scheid (Eds.), The handbook of the study of mental health: Social contexts, theories, and systems (pp. 348-360). Cambridge: Cambridge University Press.

Rosenfield, S., Lennon, M. C., \& White, H. R. (2005). The self and mental health: Self-salience and the emergence of internalizing and externalizing problems. Journal of Health and Social Behavior, 46, 323-340.

Scheid, T. L., \& Horwitz, A. V. (1999). Introduction to part II. The social context of mental health and illness. In A. V. Horwitz \& T. L. Scheid (Eds.), The handbook of the study of mental health: social contexts, theories, and systems (pp. 151160). Cambridge: Cambridge University Press.

Seiffge-Krenke, I. (1993). Coping behavior in normal and clinical samples: More similarities than differences? Journal of Adolescence, 16, 285-303.

Seiffge-Krenke, I., \& Klessinger, N. (2000). Long-term effects of avoidant-coping on adolescents' depressive symptoms. Journal of Youth and Adolescence, 29, 617-630.

Sweeting, H., \& West, P. (1994). The patterning of life events in mid- to late-adolescence: Markers for the future? Journal of Adolescence, 17, 283-304.

Thoits, P. A. (1995). Stress, Coping, and Social Support Processes: Where Are We? What Next? Journal of Health and Social Behavior Extra Issue, 53-79.

Turner, R. J., \& Avison, W. R. (1989). Gender and depression: Assessing exposure and vulnerability to life events in a chronically strained population. Journal of Nervous and Mental Disease, 177, 443-455.

Turner, R. J., Wheaton, B., \& Lloyd, D. A. (1995). The epidemiology of social stress. American Sociological Review, 60, 104-125.

Udry, J. R. (2004). References, instruments, and questionnaires consulted in the development of the add health in-home adolescent interview. Accessed September 26, 2004 at http://www. cpc.unc.edu/projects/addhealth/files/refer.pdf

Van Gundy, K. (2002). Gender, the assertion of autonomy, and the stress process in young adulthood. Social Psychological Quarterly, 65, 346-363.

Washburn-Ormachea, J. M., Hillman, S. B., \& Sawilowsky, S. S. (2004). Gender and gender-role orientation differences on adolescents' coping with peer stressors. Journal of Youth and Adolescence, 33, 31-40.

Wheaton, B. (1983). Stress, personal coping resources, and psychiatric symptoms: An investigation of interactive models. Journal of Health and Social Behavior, 24, 208-229.

\section{About the Author}

Lisa A. Kort-Butler is an assistant professor of sociology at the University of Nebraska-Lincoln. She received a Ph.D. in sociology from North Carolina State University. Her current research examines sex differences in adolescent well-being, particularly delinquency and depression, focusing on variations in stress and social/personal resources. She is also interested the role of personality constructs in general strain theory. 